\title{
Renal arteriovenous fistula masquerading as severe valvar heart disease
}

\author{
ROBERT GLASER, ROBERT J. KRAMER, ROBERT I. HAMBY, \\ AGOP AINTABLIAN, AND STEVEN M. ZELDIS
}

From the Department of Medicine, Cardiology Division, Long Island fewish-Hillside Medical Center, New Hyde Park, New York; Queens Hospital Center Affiliation, Famaica, New York; and School of Medicine, Health Sciences Center, State University of New York at Stony Brook, Stony Brook, New York, USA

SUMMARY Two patients with renal arteriovenous fistulae are described, who presented in high output failure. Murmurs were detected in these patients on routine physical examination years before, and when cardiac failure ensued they were assumed to have decompensated valvar heart disease. Full investigation revealed the arteriovenous fistulae and both patients made a good recovery after surgical ligation.

An arteriovenous fistula occurring after abdominal surgery is uncommon and may escape detection, unless the characteristic murmur is sought and angiographic studies performed. We report 2 patients in whom renal arteriovenous fistulae followed nephrectomy and resulted in signs and symptoms consistent with severe valvar heart disease.

\section{Case reports}

\section{CASE 1}

A 61-year-old woman had a 10-year past history of dyspnoea on exertion. Six years previously a heart murmur had been detected on routine examination. In the following year hypertension was noted, and treatment was started with salt restriction, diuretic, and methyldopa. Four months before admission she developed congestive heart failure and was started on digoxin, but despite this she presented in pulmonary oedema one month later. There was no past history of rheumatism or coronary heart disease, but she had had multiple abdominal surgical procedures, including a right nephrectomy in 1960 for renal tuberculosis and nephrolithiasis.

Physical examination showed a blood pressure of $160 / 60 \mathrm{mmHg}$, with a regular pulse of 80 per minute. The carotid upstroke was brisk and full. Lungs were clear. A hyperdynamic apical impulse was palpable in the sixth left intercostal space. A systolic thrill was present, maximal at the lower left sternal border. On auscultation, the first sound was

Received for publication 26 January 1978 normal, the second sound narrowly split, and aortic closure slightly accentuated. A harsh grade $3 / 6$ midsystolic murmur was loudest in the second right intercostal space; a grade $4 / 6$ continuous murmur was heard over the entire chest posteriorly loudest over the right costovertebral angle, and in the right upper abdominal quadrant anteriorly where a continuous thrill was present. Loud third and fourth sound gallops were also noted. There was no hepatosplenomegaly. Mild oedema of the ankles was present.

The electrocardiogram showed normal sinus rhythm, left atrial abnormality, and increased QRS voltages denoting left ventricular hypertrophy. Chest $x$-ray films showed cardiomegaly with left ventricular and left atrial enlargement and prominent pulmonary vascular markings.

Cardiac catheterisation showed raised right heart pressures. No left or right shunt was detected with the hydrogen electrode. The cardiac output was $10.75 \mathrm{l} / \mathrm{min}$, with cardiac index $6.60 \mathrm{l} / \mathrm{min}$ per $\mathrm{m}^{2}$. There was a wide aortic pulse pressure of 120 mmHg. Left ventricular end-diastolic pressure was raised to $32 \mathrm{mmHg}$. There was no gradient $\tilde{O}$ across the aortic valve. Left ventriculogram showed $\underset{\omega}{N}$ normal contractility with minimal mitral regurgita- 0 tion. Ascending aortography showed no aortic 6 regurgitation. The coronary arteries were normal. Abdominal aortogram disclosed a right renal artery of fistula to the inferior vena cava (Fig. 1). The fistula 0 was closed at operation. The patient tolerated the procedure well and since then has been asymptomatic. After operation, no murmur has been heard. Chest $x$-ray films have shown a decrease in heart size without congestive changes. 


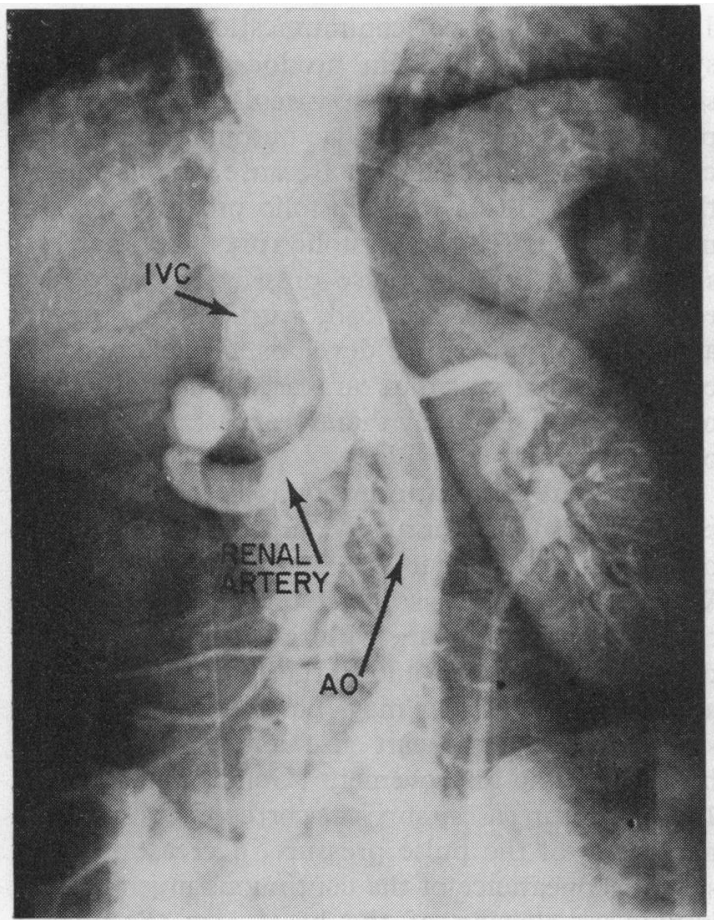

Fig. 1 Case 1. Abdominal aortogram shows normal aorta (AO). The right kidney is absent. Both renal arteries are seen, with the right renal artery greatly enlarged, and there is immediate filling of the inferior vena cava (IVC) comparable with a central arteriovenous fistula.

\section{CASE 2}

A 66-year-old woman had a right nephrectomy at the age of 26 for renal tuberculosis. Three years before admission, she developed exertional dyspnoea associated with a sensation of pressure in the chest, and on examination a heart murmur was noted. She became more breathless and presented in congestive heart failure with atrial fibrillation. She improved with treatment and was then referred for further evaluation.

On examination the blood pressure was $165 / 70$ $\mathrm{mmHg}$ and the pulse regular at 74 per minute. The peripheral pulses were brisk and full. The lungs were clear. A sustained cardiac apical impulse was palpable in the sixth left intercostal space in the anterior axillary line. A systolic thrill was present and maximal at the base. On auscultation, the first sound was normal, and the second sound narrowly split with aortic closure slightly diminished. A grade 5/6 harsh, midsystolic murmur was heard at the second right intercostal space and radiated to the neck, and there was a grade $2 / 6$ descrescendo diastolic murmur at the left sternal border; a grade 4/6 continuous murmur and thrill was maximal

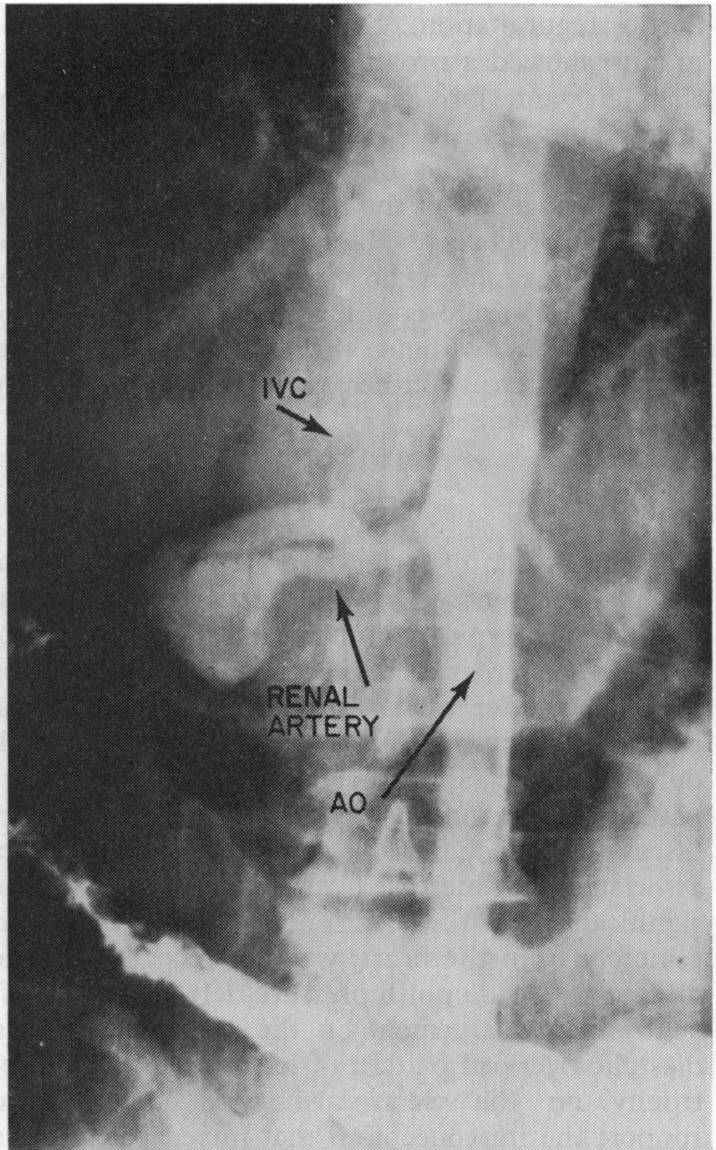

Fig. 2 Case 2. Abdominal aortogram with catheter in aorta $(A O)$ at level of renal arteries. The right renal artery is enlarged and there is early filling of inferior vena cava (IVC) from tortuous renal artery to inferior vena cava fistula.

in the right upper abdominal quadrant and radiated widely to the chest, back, and praecordium. There was no hepatosplenomegaly and no peripheral oedema.

Electrocardiogram showed normal sinus rhythm, left atrial abnormality, and voltage changes of left ventricular hypertrophy. Chest $x$-ray films showed cardiomegaly with left atrial and ventricular enlargement and increased pulmonary vascularity.

Cardiac catheterisation showed minimal aortic valve calcification. Right heart pressures were raised. Cardiac output was $13.811 / \mathrm{min}$, with cardiac index 8.15 $1 / \mathrm{min}$ per $\mathrm{m}^{2}$. There was a peak aortic valve gradient of $24 \mathrm{mmHg}$. Left ventricular end-diastolic pressure was $11 \mathrm{mmHg}$. Left ventriculogram showed normal contractility, with no mitral regurgitation, and aortogram showed no 
aortic regurgitation. Selective coronary arteriography showed a proximal 50 per cent stenosis of the left anterior descending artery. Abdominal aortography revealed a large fistula from the right renal artery to the inferior vena cava (Fig. 2). Surgical resection of the fistula was followed by an uneventful recovery. The patient is now asymptomatic and requires no cardiac medications. On examination, there is still a grade $2 / 6$ midsystolic murmur, but without thrill. Chest $x$-ray films showed a decrease in heart size and no pulmonary congestive changes.

\section{Discussion}

The diagnosis of arteriovenous fistula may be readily apparent when the history and clinical findings are typical (Gomes and Bernatz, 1970). When a major arterial to venous fistula develops insidiously after earlier surgical intervention, the causative event may not be appreciated and high output cardiac failure may be overlooked. In our patients an erroneous diagnosis of valvar heart disease was made initially, because of the murmurs associated with increased cardiac output. Thus, the significance of the continuous murmur, located remotely from the heart, was not recognised. The finding of a wide pulse pressure, left atrial and left ventricular enlargement on the $x$-ray film, and a diastolic overload pattern of left ventricular hypertrophy on the electrocardiogram appeared to support the misconception that mixed aortic valve disease was the major anatomical defect. Only one such case of a renal arteriovenous fistula mimicking valvar heart disease has been published (Blesa et al., 1976).

Renal arteriovenous fistulae may result from mass ligation of the artery and vein. Such fistulae may develop particularly when transfixing sutures are used which may pass through both structures establishing a potential tract along which a communication can develop (Aravanis et al., 1962). Perioperative infection is another factor implicated in the genesis of surgical arteriovenous fistulae (Gitlitz et al., 1963). The interval between fistula formation and development of high output cardiac failure is variable, with duration and size of shunt the primary determining factors (Shirey, 1959). Onset of symptoms in post-nephrectomy arteriovenous fistula ranges from 5 months to 35 years, with a mean of 15 years (Joseph et al., 1972). In our second patient, there was a 40 -year interval between nephrectomy and detection of an arteriovenous fistula.

The physiology of arteriovenous fistula has been extensively studied (Holman, 1923; Krumharr et al.,
1974). The abnormal communication between the systemic artery and vein produces a left-to-right shunt with perfusion of a vascular bed with low peripheral resistance. Cardiac output increases as a compensatory mechanism. Because of the run-off through the fistula, the diastolic pressure remains normal or falls, the systolic pressure increases significantly, and the pulse pressure widens. As a result of diastolic overload, cardiomegaly ensues and high output failure develops. Systolic ejection or regurgitant murmurs are accentuated by high output failure, and may therefore mask the presence of an arteriovenous fistula.

Treatment of an arteriovenous fistula consists of primary closure of the artery and vein, and resection ot any associated aneurysm (Cummings et al., 1975). When detected, the fistula should be excised before cardiac hypertrophy and failure develop. Prolonged delay in recognition and surgical treatment of an arteriovenous fistula may be followed by only slight decrease in heart size and result in little haemodynamic improvement (Gomes and Bernatz, 1970). In our cases, surgical correction resulted in narrowing of the pulse pressure, decrease in heart size, disappearance of the continuous murmur, and immediate slowing of the heart rate (Branham's sign). In addition, the praecordial flow murmurs decreased and heart failure resolved after ligation of the fistula. Though in our cases cardiac auscultation disclosed systolic and diastolic murmurs associated with increased flow, the continuous murmur was not apparent on praecordial examination but only on auscultation of areas remote from the heart. The increase in murmur intensity on remote examination compared with praecordial auscultation is a clue that a non-cardiac vascular anomaly may be present. This has been previously emphasised as a useful diagnostic sign in peripheral pulmonary stenosis and other extracardiac lesions (Perloff and Lebauer, 1969).

In conclusion, arteriovenous fistula should be suspected in patients with surgical incisions and a continuous murmur. Recognition of a remote continuous murmur heard best over a surgical incision should suggest this unusual cause of insidious congestive heart failure.

\section{References}

Aravanis, C., Michaelides, G., Alivizatos, C. N., and Lazarides, D. (1962). Renal arteriovenous fistula following nephrectomy. Annals of Surgery, 156, 749-751.

Blesa, E. S., Kreulen, T. H., Perlstein, E., Escovitz, E. S., and Tyson, R. R. (1976). Systemic arteriovenous fistula simulating severe valvular aortic stenosis. Chest, 70, 88-90. Cummings, K. B., Jolly, P. D., Graber, J. O., and Burnett, L. L. (1975). Arteriovenous fistula of the renal vessels: surgical management. fournal of Urology, 114, 776-778. 
Gitlitz, G. F., Fell, S. C., Sagerman, R. H., and Hurwitt, E. S. (1963). Post-nephrectomy arteriovenous fistula: case report and review of the literature. Annals of Surgery, 157, 511-515.

Gomes, M. M. R., and Bernatz, E. P. (1970). Arteriovenous fistulae: a review and ten-year experience at the Mayo Clinic. Mayo Clinic Proceedings, 45, 81-102.

Holman, E. F. (1923). Physiology of an arteriovenous fistula. Archives of Surgery, 7, 64-82.

Joseph, R. S., Lubell, D. L., and Lambrew, C. T. (1972). Postnephrectomy arteriovenous fistula. New York Stale Fournal of Medicine, 72, 2209-2214.

Krumharr, D., Schmidt, H. D., and Schulz, U. (1974) Acute and chronic flow measurements in experimental arterio. venous fistulas. Basic Research in Cardiology, 69, 447-461.

Perloff, J. K., and Lebauer, E. J. (1969). Auscultatory and phonocardiographic manifestations of isolated stenosis of the pulmonary artery and its branches. British Heart fournal, 31, 314-321.

Shirey, E. K. (1959). Cardiac disease secondary to postnephrectomy arteriovenous fistula. Cleveland Clinic Quarterly, 26, 188-200.

Requests for reprints to Dr Robert J. Kramer, Cardiology Division, Long Island Jewish-Hillside Medical Center, New Hyde Park, N.Y. 11040, USA. 